market would have the unwanted effect of causing illegal trafficking. Regulations regarding fossil finds are necessary.

In Italy, these are very strict: like archaeological objects, fossils belong to the state and cannot be sold. However, their monetary value is decided by professionals appointed by an archaeological board; a small percentage of the sum is then divided between the discoverer and the owner of the land where the fossil was found. This law has proved efficient in protecting our natural and cultural heritage.

Elisabetta Cioppi, Stefano

Dominici Museo di Storia Naturale dell'Università di Firenze, Sezione di Geologia e Paleontologia, Via La Pira 4, 50121 Firenze, Italy

e-mail: elisabetta.cioppi@unifi.it

\section{'Snow joke as festive season gives rise to a blizzard of fake flakes}

Parts of the world are once again knee-deep in images of snow crystals for the Christmas and New Year festivities.

Unfortunately, the grand diversity of naturally occurring snow crystals is commonly corrupted by incorrect 'designer' versions - as illustrated by the faux octagonal snowflakes depicted in a Nature online subscription advertisement and, ironically, captioned "...for anyone who loves science".

The snowflake's natural sixfold symmetry stems from the water molecules' hexagonal crystal lattice, held together by a hydrogen-bonding network and the structural form of lowest energy under the ambient cold conditions. This hexagonal shape has been known since at least 400 years ago, when the astronomer Johannes Kepler published a treatise on the subject On the Six-cornered Snowflake (De nive sexangula Tampach; 1611), as a new-year's gift to his patron modern editions are still available.

Beautiful photographs abound,

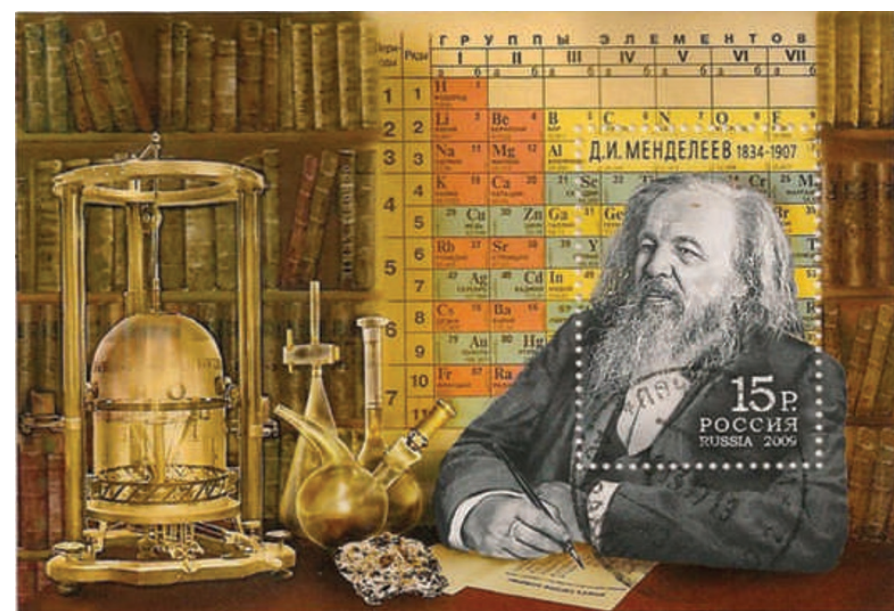

\title{
A toast to Mendeleev, who merits more than periodic honour
}

Before the year is out, let's raise a glass to the great Russian chemist Dmitrii Mendeleev, to celebrate the 140th anniversary of his periodic table of the elements. Russia has commemorated this, and the 175th anniversary of Mendeleev's birth, with a postage stamp (pictured) and a two-rouble silver coin.

Mendeleev's outstanding achievement was to organize all the chemical knowledge of the

including those taken by Vermont farmer Wilson A. Bentley starting in 1885 (W. A. Bentley \& J. Humphreys Snow Crystals McGraw-Hill; 1931), or see www. snowcrystals.com. Why then do many artists invent their own physically unrealistic snow crystals?

We who enjoy both science and captivating design should aim to melt away all four-, five- or eightcornered snow crystals from cards, children's books and advertisements, by enlightening those who unwittingly generate and distribute them. Let's welcome this as an opportunity to share a discussion about the true beauty of science over a mug of hot punch.

Thomas Koop Department of Chemistry, Bielefeld University, 33615 Bielefeld, Germany e-mail:thomas.koop@uni-bielefeld.de

\section{Rewilding can cause rather than solve ecological problems}

Prehistoric-restoration schemes such as those described in your News Feature (Nature 462, 30-32; 2009) are highly unusual. Introducing a mix of native and exotic ungulates into former agricultural land could constitute a risky conservation strategy.

Reintroduction of native species to portions of their former range from which they were extirpated is a well-established conservation tool. But there are no scientific grounds for introducing animals such as elephants,

camels, cheetahs and lions into novel environments. Numerous scientifically driven concerns bear on these maverick programmes, including adverse effects of alien species on the ecosystems they are meant to foster; importation of diseases that may leap to native species; escapes that lead to hybridization; and predators jumping fences to endanger livestock.

There are sociopolitical concerns too, such as plundering wildlife from countries and ecosystems where they are naturally found in order to stock game parks, and persuading a conservation-weary public to accept large charismatic exotics as substitutes for contemporary native species and ecosystems.

We therefore advocate a moratorium on importing non- indigenous megafauna into ecosystems. III-considered, poorly documented introductions cannot be trusted to turn back the ecological and evolutionary clocks on anthropogenic change.

Tim Caro Department of Wildlife,

Fish and Conservation Biology, University of California, Davis, California 95616, USA e-mail: tmcaro@ucdavis.edu Paul Sherman Department of Neurobiology and Behavior, Cornell University, Ithaca, New York 14853, USA day into a single table and to predict the existence of new elements such as scandium, gallium and germanium. His periodic table, published in 1869 , contained empty spaces to accommodate these as-yet undiscovered chemical elements.

Mendeleev's periodic law and periodic table of the elements were welcomed by the world's scientific community, and yet he received scant recognition for his work during his lifetime. He was never awarded a Nobel prize, for example. And the third Tsar Alexander is said to have blocked Mendeleev's election as a full member of the Russian Academy of Sciences, although he was allowed to continue as a corresponding member.

However, Mendeleev has been recognized more recently. This year, the American Chemical Society celebrated his periodic table during its national chemistry week, with the theme 'Chemistry - it's elemental'.

In keeping with terms such as Newtonian mechanics, Darwinian theory, Mendelian genetics and Watson-Crick hydrogen bonding, should the world not honour Mendeleev by referring to his achievement as the 'Mendeleev periodic table of the elements'?

Renad I. Zhdanov Functional Genomics and Lipidomics Lab, Institute of General Pathology and Pathophysiology, 8 Baltiiskaya Street, Moscow 125315, Russia e-mail:zrenad@gmail.com 